a) Infrared optics, luminescence, photoconductivity.

\title{
REVIEW OF OPTICAL APPLICATIONS OF CdTe
}

\author{
R. O. BELL \\ Mobil Tyco Solar Energy Corporation 16 Hickory Drive \\ Waltham, Massachusetts 02154 U. S. A.
}

\begin{abstract}
Résumé. - Le tellurure de cadmium possède des propriétés qui rendent ce matériau intéressant en vue d'applications optiques telles que les modulateurs électro-optiques, les fenêtres pour laser de puissance, les dispositifs électroluminescents et photoconducteurs. Dans cet article de synthèse on passera en revue l'ensemble de ces applications après avoir considéré en détail les mécanismes d'absorption de la lumière dans ce composé et étudié l'influence des impuretés sur les propriétés optiques du matériau.
\end{abstract}

Abstract. - CdTe is a material potentially useful for a number of optical applications. These include electrooptic modulation, high power laser windows, electroluminescence and photoconduction. In this review these and other uses will be described. Particular attention will be paid to the various optical absorption mechanisms and the effects of impurities on the optical behavior.

1. Introduction. - CdTe has a very low optical absorption from its bandedge at $0.85 \mu \mathrm{m}$ to near the edge of the reststrahl band at $30 \mu \mathrm{m}$. For wavelengths longer than $200 \mu \mathrm{m}$ it is transparent. Its zincblende $(\overline{4} 3 \mathrm{~m})$ structure allows an electrooptic coefficient which

\section{TABLE I}

Some general properties of $\mathrm{CdTe}$
Lattice Parameter

Density

Thermal Expansion Coefficient

$(300 \mathrm{~K})\left(^{a}\right)$

Specific Heat $\left({ }^{b}\right)$

Thermal Conductivity $(300 \mathrm{~K})\left({ }^{c}\right)$

Thermal Conductivity $(80 \mathrm{~K})\left(^{c}\right)$

Refractive Index $(10.6 \mu \mathrm{m})\left({ }^{d}\right)$

Reflectivity $(10.6 \mu \mathrm{m})\left({ }^{d}\right)$

Longitudinal Optical Phonon Energy $\left({ }^{e}\right)$

Transverse Optical Phonon Energy $\left({ }^{d}\right)$

Relative Dielectric Constant $\left({ }^{d}\right)$

Energy Gap (300 K) $\left(^{f}\right)$

Energy Gap (4 K) $\left(^{f}\right)$

Mobility-Electrons $(300 \mathrm{~K})\left(^{g}\right)$

Mobility-Holes (300 K) ${ }^{(g}$ )
$6.481 \AA$

$5.852 \mathrm{~g} \mathrm{~cm}^{-3}$

$4.96 \times 10^{-6}{ }^{\circ} \mathrm{C}^{-1}$

$0.044 \mathrm{cal} \mathrm{g}^{-1} \mathrm{o}^{-1}$

$0.075 \mathrm{~W} \mathrm{~cm}^{-1}{ }^{\circ} \mathrm{C}^{-1}$

$0.44 \mathrm{~W} \mathrm{~cm}^{-1}{ }^{\circ} \mathrm{C}^{-1}$

2.64

0.203

$21.3 \mathrm{meV}(58.2 \mu \mathrm{m})$

$17.4 \mathrm{meV}(71.4 \mu \mathrm{m})$ 10.6

$1.529 \mathrm{eV}$

$1.606 \mathrm{eV}$

$1200 \mathrm{~cm}^{2} \mathrm{~V}^{-1} \mathrm{~s}^{-1}$ $100 \mathrm{~cm}^{2} \mathrm{~V}^{-1} \mathrm{~s}^{-1}$ (a) Williams, M. G., Tomlinson, R. D. and Hampshire, M. J. Solid State Commun. 7 (1969) 1831.

(b) WeIt, R. and Johnson, C. J., J. Appl. Pnys. 40 (1969) 4681.

(c) Slack, G. A. and Galginaitis, S., Phys. Rev. 133 (1964) A 253.

(d) Ref. 2.

(e) Halsted, R. E., Lorenz, M. R. and Segall, B., J. Phys. Chem. Solids 22 (1961) 109.

(f) Ref. 7.

${ }^{(g)}$ De Nobel, D., Philips Res. Rep. 14 (1959) 361. turns out to be large compared to GaAs and other III-V's. It thus makes an excellent modulator for the $10.6 \mu \mathrm{m} \mathrm{CO}{ }_{2}$ laser. CdTe has a direct bandgap and can be doped both n- and p-type so it has potential, as yet unrealized, as a p-n junction electroluminescent laser. Electron beam and double photon optical pumping, though, have been used to produce stimulated emission with the former even at room temperature.

Some of the general physical and optical properties of CdTe are shown in table I. Details relative to more specific optical characteristics are presented below.

No discussion of optical applications would be complete without a review of optical absorption mechanisms. This is the subject of the first section. The second section discusses the actual applications beginning with infrared windows, continuing with electrooptic modulation and non-linear optics, and concluding with a part on luminescence and photoconductivity.

Solar cells could be construed as an optical application but they have been excluded since they are covered in detail in another part of these Proceedings.

2. Optical absorption. - The transmission range of CdTe is determined on the short wavelength limit by the electronic energy gap and on the long wavelength limit by lattice vibrations. Within this broad range, the optical transmission of an uncoated slice with low absorption and at normal incidence is approximately $63 \%$. For wavelengths longer than about $200 \mu \mathrm{m}$ CdTe again becomes transparent but because of the higher dielectric constant has a slightly lower $(52 \%)$ transmission $[1,2]$.

The four principal factors that produce infrared optical loss in CdTe are (1) interband electronic transitions ; (2) fundamental and harmonic lattice vibrations, 
including multiphonon processes ; (3) impurity absorption, either by electrons bound to defects, localized optical impurity modes, or inner shell electronic transitions ; and (4) free carrier absorption. A fifth factor, which in practice often dominates and consists of scattering losses from precipitates, inclusions, voids or strains, will not be considered since we will assume, somewhat fatuously, that it is the responsibility of the crystal grower. In fact annealing studies by Gentile et al. [3] lead him to hypothesize that precipitates are the primary optical loss mechanism at $10.6 \mu \mathrm{m}$ in carefully prepared CdTe.

2.1 INTERBAND ELECTRONIC TRANSITIONS. - The electronic energy band structure [4] is shown in figure 1 .

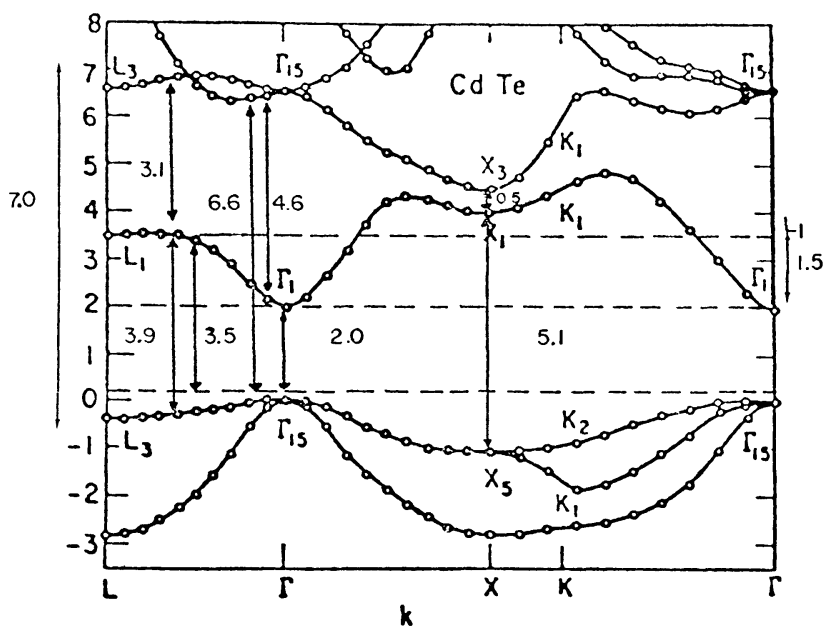

Fig. 1. - Energy band structure of CdTe at $0 \mathrm{~K}$ (after M. L. Cohen and T. K. Bergstresser [4]).

The energy gap is direct and involves a transition from $\Gamma_{15}$ to $\Gamma_{1}$. Numerous absorption measurements have been made near the band edge [5,6]. Figure 2 shows room temperature absorption measurements made on evaporated, high resistivity films at Mobil Tyco Solar Energy Corporation. The absorption coefficient at long wavelengths varied from sample to sample and is probably as closely related to the impurity content as to the band structure. Camassel et al. [7] conclude on the basis of photoluminescent measurements that at room temperature $(300 \mathrm{~K})$ the optical bandgap is $1.529 \mathrm{eV}$ with a temperature coefficient of $-3 \times 10^{-4} \mathrm{eV} / \mathrm{K}$. At liquid $\mathrm{He}$ the bandgap is $1.606 \mathrm{eV}$.

2.2 Fundamental LATtice abSORPtion. - Optical absorption can arise from the coupling of the fundamental lattice vibrations to optical photons. Standard dispersion theory is often used to express the variation of the dielectric constant or index of refraction (both the real and imaginary parts) in terms of an assembly of damped harmonic oscillators [8]. Refraction and absorption data can be reasonably well characterized by such expressions close to the normal modes, but classical dispersion theory breaks down in

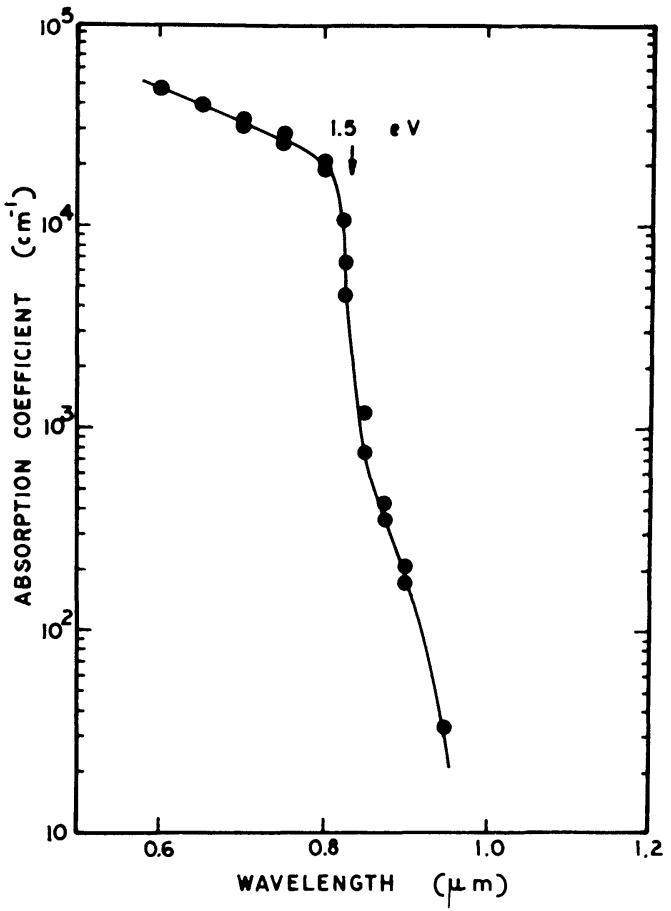

FIG. 2. - Optical absorption coefficient versus wavelength as measured on evaporated CdTe films.

regions far from the lattice modes $[9,10]$. In general the quantized features of the phonons and photons must be considered. Classical theory tends to greatly over estimate losses in the wings. Only by replacing the damping constant by a term with an exponential frequency dependence can agreement with experiments be obtained [10].

The absorption index, $\beta_{1}$, can be described at frequencies, $\omega$, above the normal modes by

$$
\beta_{1}=\beta_{0} \exp \left(-\omega / \omega_{0}\right)
$$

where $\beta_{0}$ and $\omega_{0}$ are material dependent constants. The absorption index is related to the absorption coefficient, $\alpha$, by $\beta_{1}=\alpha \lambda / 4 \pi$ where $\lambda$ is the wavelength. Empirically it has been found [10] that for binary compounds $\omega_{0}=\gamma \omega_{t}$ where $\omega_{t}$ is the reststrahl frequency, $\gamma$ is between 0.4 and 0.3 , and $\beta_{0}$ is of the order of 5 .

The behavior of $\beta_{1}$ can be explained if the photon is dissipated simultaneously into $n$ phonons such that energy is conserved. Assuming that only one acoustic branch couples to the photons, the absorption probability has the correct form when a number of phonons, such as 3 or more are involved. For multiphonon processes the selection rules are sufficiently loose so the optical absorption will be nearly continuous because the phonon distribution in energy is continuous.

An estimate using $\lambda_{\mathrm{t}}=72 \mu \mathrm{m}, \beta_{0}=5$, and $\gamma=0.3$ gives $\alpha=10^{-5} \mathrm{~cm}^{-1}$ at $10.6 \mu \mathrm{m}$. Experimental values as low as $2 \times 10^{-4} \mathrm{~cm}^{-1}$ have been reported at this wavelength [11]. Sparks and Sham [12] have developed a more complete theory and estimate the lower limit due to multiphonon processes to be the order of $10^{-8} \mathrm{~cm}^{-1}$. 
2.3 IMPURITY RELATED ABSORPTION. - When an impurity is present in a semiconductor such as CdTe, several different processes can give rise to optical absorption in the region between the energy gap and lattice vibration bands. For example, excitation of an electron (hole) bound to a localized center or defect to the conduction (valence) band is possible. For most applications impurities or defects are necessary to control the conductivity of the CdTe and thus it is important that these species not introduce significant absorption levels where they are not desired. For moderate doping levels $\left(10^{17} \mathrm{~cm}^{-3}\right)$, the associated absorption will generally be low. Shallow donors and acceptors will not absorb for wavelengths much longer than the energy gap. Figure 3 shows some of the

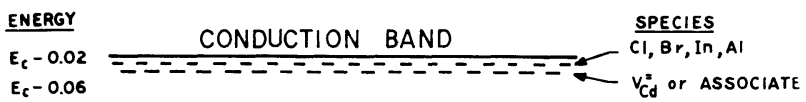

$\mathrm{E}_{\mathrm{c}-0.06}--------\leftarrow \mathrm{v}_{\mathrm{cd}}^{2}$

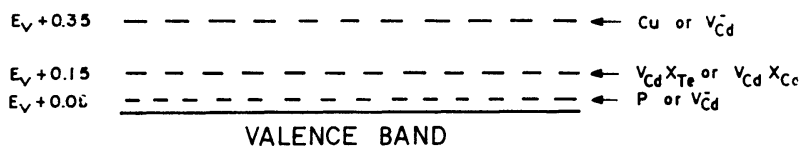

FIG. 3. - Energy level diagram of some of the electrical levels in the forbidden energy gap. A tentative identification of the possible species is on the right hand side.

reported electrically active centers in $\mathrm{CdTe}$ and possible identifications. Since almost every level has been ascribed to several different species, this assignment is quite tentative and only reflects my personal opinion.

- It has been found that donor impurities such as In and $\mathrm{Ga}$ shift the apparent absorption edge to longer wavelengths. Brodin et al. [13] concluded that the donor impurities at high concentration deform the valence band and produce a donor impurity band even in compensated CdTe. Doping levels as low as $5 \times 10^{16} \mathrm{~cm}^{-3}$ are enough to produce an observable shift [13, 14]. Apparently acceptors do not produce such a large shift, probably because the density of states in the valence band is much larger than in the conduction band.

Introduction of light atoms such as Se for Te $[15,16]$ or $\mathrm{Al}$ for $\mathrm{Cd}$ [17] can produce localized lattice modes. For Se the impurity peak is on the long wavelength side $(58 \mu \mathrm{m})$ of the CdTe transverse optical absorption [15, 16]. For the case of $\mathrm{Al}$ on a $\mathrm{Cd}$ site, a number of modes between about 31 and $30 \mu \mathrm{m}$ were found [17]. Different frequencies were measured depending upon the degree of association of $\mathrm{Al}$ with $\mathrm{Cd}$ or other impurities or defects.
Another absorption mechanism that arises from impurities occurs for transitions between electronic levels of a ground state ion (split by spin orbit coupling for example). Slack et al. [18] have studied the behavior of tetrahedral $\mathrm{Fe}^{2+}$ in CdTe and found a single broad absorption between 1.3 and $6.7 \mu \mathrm{m}$ at room temperature [18]. Vul et al. [19] found two bands - one at 3.5 and the other at $0.92 \mu \mathrm{m}$ which they attributed to electronic transitions (Fig. 4). Other such metals

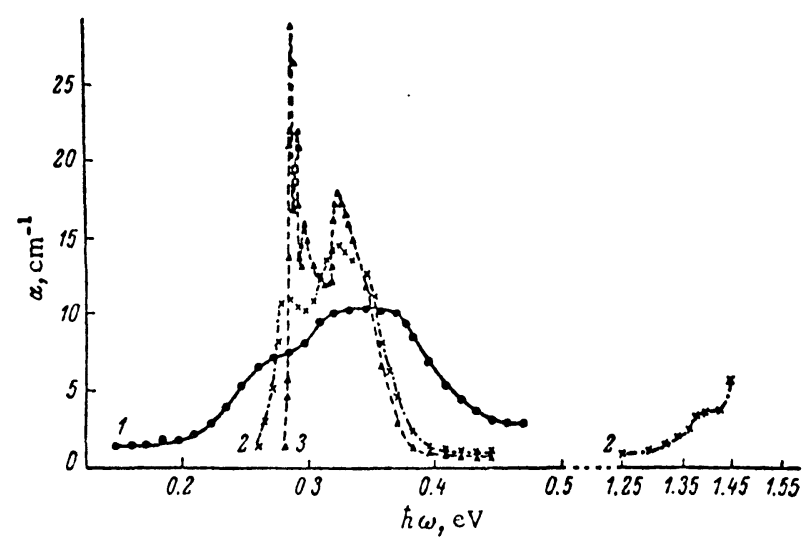

FIG. 4. - Optical absorption of CdTe doped with $\mathrm{Fe}$ at 1) $300 \mathrm{~K}$, 2) $90 \mathrm{~K}$ and 3) $20 \mathrm{~K}$ (after B. M. Vul et al. [19]).

studied in $\mathrm{CdTe}$ include $\mathrm{Ti}, \mathrm{V}$, and $\mathrm{Cr}[20,21]$. Absorption spectra due to transitions within the $3 d$ shell were observed.

2.4 FREE CARRIER ABSORPTION. - Free carrier absorption arises from the interaction of optical phonons and the nearly free electrons and holes. In semiconductors at long wavelengths or if a low absorption coefficient is necessary, this loss mechanism can be important.

The general form of the relationship between the carrier concentration, $N$, the real part of the index of refraction, $n$, and the imaginary part, $\beta$, can be obtained rather simply from the classical treatment of a harmonically bound electron subjected to an applied electric field of frequency $\omega$, with the result [8].

$$
\begin{aligned}
n^{2}-\beta^{2}-\varepsilon & =\frac{N e^{2} / m^{*} \varepsilon_{0}}{\omega^{2}+g^{2}} \\
2 n \beta \omega & =\frac{g N e^{2} m^{*} \varepsilon_{0}}{\omega^{2}+g^{2}}=c n \alpha
\end{aligned}
$$

$g$ is $\varepsilon / \mu m^{*}, \varepsilon$ is the relative dielectric constant, $\varepsilon_{0}$ is the permitivity of free space, $e$ is the electronic charge, $m^{*}$ is the effective mass and $\mu$ is the mobility.

If $\omega \mu m^{*} / e \gg 1$, which is generally valid for wavelengths in the infrared, the expression for the absorption coefficient becomes after generalizing for holes and electrons,

$$
\alpha=\frac{\lambda^{2} e^{3}}{4 \pi^{2} c^{3} n \varepsilon_{0}}\left[\frac{N_{\mathrm{n}}}{m_{\mathrm{n}}^{*^{2}} \mu_{\mathrm{n}}}+\frac{N_{\mathrm{p}}}{m_{\mathrm{p}}^{*^{2}} \mu_{\mathrm{p}}}\right] .
$$


TABLE II

Properties of selected materials necessary to calculate figure of merit for high power laser windows (after Ref. [11])

\begin{tabular}{|c|c|c|c|c|c|c|}
\hline Materials & $\begin{array}{l}\alpha\left(\mathrm{cm}^{-1}\right) \\
(10.6 \mu \mathrm{m})\end{array}$ & $\begin{array}{c}K \\
\left(\mathrm{~W} \mathrm{~cm}-1 \mathrm{~K}^{-1}\right)\end{array}$ & $\left(\begin{array}{c}\alpha_{\mathrm{T}} \\
\left(10^{-6} \mathrm{~K}^{-1}\right)\end{array}\right.$ & $\left(\begin{array}{c}\sigma_{\mathrm{c}} \\
\left(\mathrm{K} \mathrm{g} \mathrm{cm}^{-2}\right)\end{array}\right.$ & $\begin{array}{c}E \\
\left(\mathrm{~K} \mathrm{~g} \mathrm{~cm}^{-2}\right) \\
\left(\times 10^{4}\right)\end{array}$ & $\begin{array}{c}{ }^{\chi} \\
\left(\mathrm{K}^{-1}\right) \\
\left(\times 10^{6}\right)\end{array}$ \\
\hline GaAs & $0 . \overline{008}$ & 0.48 & $\overline{5.7}$ & $\overline{1400}$ & 87 & 160 \\
\hline $\mathrm{ZnSe}$ & 0.001 & 0.18 & 8.5 & 560 & 70 & 67 \\
\hline Diamond & 0.06 & 20 & 0.8 & 42000 & 1020 & 10 \\
\hline $\mathrm{KCl}$ & 0.00007 & 0.6 & 36 & 45 & 30 & -5 \\
\hline CdTe & 0.0002 & 0.07 & 5.9 & 320 & 24 & 120 \\
\hline
\end{tabular}

In a quantum mechanical treatment an electron in the periodic field of a crystal lattice cannot absorb radiation unless lattice vibration scattering, such as from the acoustic modes, polar modes, optical phonons, internal scattering or ionized impurities occurs. Expressions for a number of different scattering mechanisms have been derived, but the form of eq. (3) is basically correct if the collision time is independent of energy.

Experimentally the free carrier absorption is usually specified by fitting an expression of the form

$$
\alpha=A N \lambda^{p}
$$

where $A$ is a constant, $\lambda$ is the wavelength, and $p$ expresses the wavelength dependence. Classically $p=2$ but Plotnikov et al. [22] find $p=5 / 2$ in n-type CdTe doped with A1. Strauss and Iseler [23] find that $p$ varies from 2.7 to 3.4 in samples doped with donors such as $\mathrm{Al}, \mathrm{Ga}, \mathrm{In}, \mathrm{Cl}$ and $\mathrm{I}$. This is reasonable for intraband, free carrier absorption produced by polar optical mode and ionized impurity scattering. Using parameters appropriate to $\mathrm{CdTe}$ at $10.6 \mu \mathrm{m}$, an absorption less than $10^{-3} \mathrm{~cm}^{-1}$ requires carrier concentrations below $10^{13} \mathrm{~cm}^{-3}$.

3. Optical applications. - 3.1 INFRARED wiNDows. - The extremely flat transmission in the infrared makes CdTe quite attractive for optical windows [11, 24]. It is inert to water vapor and has good resistance to chemical attack. It can be fabricated either in a fine grained, hot-pressed form (IRTRAN 6) [25], in polycrystalline slices or in single crystalline form with very low optical absorption at wavelengths as long as $30 \mu \mathrm{m}$. It can be used for optical components such as lenses, Brewster windows, partial reflectors and special filters. For example in the 5 to $25 \mu \mathrm{m}$ range it is nearly ideal if the visible is to be excluded [26].

One recent application has been as a material for very high power $10.6 \mu \mathrm{m}$ laser windows. One key parameter in which CdTe excels is in its very low optical loss. A very general requirement that must be fulfilled is that the window neither fail from thermal fracture nor from optical distortion.

It has been theoretically predicted that the total power of a CW laser beam, $P$, with a Gaussian profile that will produce rupture in plate is [11]

$$
P=\frac{4 \pi K}{\alpha \alpha_{\mathrm{T}} E} \sigma_{\mathrm{c}} \zeta
$$

where $K$ is the thermal conductivity, $\alpha$ is the optical absorption coefficient, $\alpha_{T}$ is the linear thermal expansion coefficient, $E$ is Young's modulus, $\sigma_{\mathrm{c}}$ is the rupture stress and $\zeta$ is a geometrical factor that depends on relative beam size and type of cooling. Thus $\sigma_{\mathrm{c}} K / \alpha \alpha_{\mathrm{T}} E$ will be a figure of merit, $\mathrm{FM}_{\mathrm{T}}$, for thermal fracture. The larger $\mathrm{FM}_{\mathrm{T}}$ the better the material. The values of parameters that make up FM for several materials are shown in table II.

Another mode by which a window can become unusable is if absorbed radiation distorts the window so much the beam becomes defocussed. For this optical distortion the figure of merit, $\mathrm{FM}_{\mathrm{O}}$, is given by $K / \alpha \chi$ where $\chi$ is an optical distortion parameter which depends primarily on the change of index of refraction with temperature, thermal expansion and stress-optic effects [11]. Values of $\alpha$ and $\chi$ are also given in table II.

Table III compares FM's for GaAs, $\mathrm{ZnSe}$, diamond, $\mathrm{KCl}$ and CdTe. With the exception of diamond, CdTe is best as far as FM $_{\mathrm{T}}$ is concerned but it is not as good as $\mathrm{ZnSe}$ or $\mathrm{KCl}$ when $\mathrm{FM}_{\mathrm{O}}$ is considered. Of course,

\section{TABLE III}

Thermal fracture and optical distortion figures of merit for selected laser window materials at $10.6 \mu \mathrm{m}$ (after Ref. [11])

\begin{tabular}{lcc} 
& \multicolumn{2}{c}{ Figure of merit } \\
& $\mathrm{FM}_{\mathrm{T}}$ & $\mathrm{FM}_{\mathrm{O}}$ \\
& $\frac{\sigma_{\mathrm{c}} K}{\alpha \alpha_{\mathrm{T}} \mathrm{E}}$ & $\frac{K}{\alpha \chi}$ \\
& $\left(\times 10^{3}\right)$ & $\left(\times 10^{5}\right)$ \\
$\mathrm{GaAs}$ & - & - \\
ZnSe & 17 & 4 \\
Diamond & 17 & 26 \\
KCl & 1700 & 340 \\
CdTe & 4 & 1860 \\
& 63 & 25
\end{tabular}


$\mathrm{KCl}$ has the severe disadvantage that it is hydroscopic and must be protected from the atmosphere. At present CdTe appears to be one of three candidates $(\mathrm{KCl}$ and ZnSe being the other two) for high power laser windows.

CdTe is deficient in the areas of thermal conductivity and rupture strength. Clearly nothing can be done about the first parameter but $\sigma_{\mathrm{c}}$ can be increased by making sufficiently fine grained CdTe. Hot pressing, chemical vapor deposition and ultrasonic casting [27] are three possible techniques to increase $\sigma_{\mathrm{c}}$ by grain refinement.

3.2 ELECTROOPTIC MODULATORS AND NONLINEAR OPTICS. - CdTe has the zincblende or $\overline{4} 3 \mathrm{~m}$ structure. Since it lacks a cente $r$ of symmetry it exhibits a linear electrooptic or Pockels effect [28, 29]. Very few electrooptic materials are transparent to $30 \mu \mathrm{m}$ so CdTe plays a unique role in this regard [29]. Antireflection coatings that give $99 \%$ or better transmission are possible within this transmission range [26].

The maximum phase retardation, $\Gamma$, obtained for light propagating in the [110] direction polarized in the [001] or [110] direction with the bias field in the [110] direction, is

$$
\Gamma=2 \pi \ln ^{3} r_{41} E / \lambda
$$

where $l$ is the sample length, $n$ the index of refraction, $r_{41}$ the electrooptic coefficient, and $\lambda$ is the wavelength. Table IV lists values of $n$ and $r_{41}$ for CdTe. Compared to GaAs, $n_{0}^{3} r_{41}$ is a factor of two larger in CdTe. The halfwave voltage, the voltage that produces a $\pi$ phase change for a unity ratio of electrode spacing to optical path length, is $53 \mathrm{kV}$ at $10.6 \mu \mathrm{m}$. Long $(60 \mathrm{~mm})$, thin $(1.5 \mathrm{~mm})$ modulators for low power applications can be made that require only $200 \mathrm{~V}$ of drive [26].

The orientation specified above provides the maximum effect per unit field and per unit length but in some cases for practical convenience this orientation is difficult to cut from existing crystals. Other orientations are possible which do not give quite the same efficiency per unit length but this may be compensated for by cutting longer bars. Several examples for various orientation of electrooptic modulator bars are shown in table V. The last column shows the reduction in

\section{TABLE IV}

\section{Electrooptic and non-linear optical properties of $\mathrm{CdTe}$ at $10.6 \mu \mathrm{m}$}

Refractive index, $n_{0}\left({ }^{a}\right)$

Electrooptic coefficient, $r_{14}\left({ }^{b}\right)$

Electrooptic characteristic

$$
n_{0}^{3} r_{41}\left(^{b}\right)
$$

Non-linear susceptibility coefficient, $d_{36}\left({ }^{c}\right)$

Dielectric loss tangent

$$
(50 \mathrm{MHz})\left({ }^{d}\right)
$$

Piezo-optic constant, $P_{11}\left(^{e}\right)$

$$
6.8 \times 10^{-12} \mathrm{mV}^{-1}
$$$$
10 \times 10^{-11} \mathrm{mV}^{-1}
$$

$$
1.5 \times 10^{-21} \mathrm{fV}^{-1}
$$$$
1.6 \times 10^{-3}
$$

$$
-0.15
$$
(a) Ref. [2].
(b) Ref. [28].
(c) Ref. [34].
(d) Ref. [31].
(e) Ref. [36]

phase shift relative to the maximum possible. For case 2 in which the electric field is along a (111) axis and no restriction, except that it be perpendicular to the (111) axis, is placed on the orientation of the bar, the efficiency is reduced by only $13 \%$.

Optical waveguide structures can be formed by proton bombardment of n-type CdTe. Low voltage modulation, more than $1^{\circ}$ per volt at $10.6 \mu \mathrm{m}$, can be achieved by biasing the structure [30].

Even at shorter wavelengths CdTe may offer some advantages over other electrooptic materials since its damage threshold is fairly high. C. Johnson reports that power densities up to $300 \mathrm{MW} / \mathrm{cm}^{2}$ for ns pulses do not produce damage, and $\mathrm{CW}$ powers up to $500 \mathrm{~W}$ are possible through a $0.6 \mathrm{~mm}$ diameter area [26].

CdTe can also be used for the internal modulation of lasers [31]. The small optical loss makes coupling modulation attractive, i. e., by generating an orthogonally polarized component of the internal laser which is reflected out of the beam by a coupler such as a Brewster angle window (Fig. 5). This technique is only

\begin{tabular}{|c|c|c|c|c|c|}
\hline Case & $\begin{array}{c}\text { Direction } \\
\text { of electric field }\end{array}$ & $\begin{array}{l}\text { Orientation } \\
\text { of length of bar }\end{array}$ & $\begin{array}{l}\text { Polarization } \\
\text { direction }\end{array}$ & $(r E)_{\mathrm{eff}}$ & $\begin{array}{l}\text { Efficiency } \\
\text { relative } \\
\text { to case } 1\end{array}$ \\
\hline 1 & (110) & $(\overline{1} 10)$ & $(110)$ or $(001)$ & $2 r E$ & $100.0 \%$ \\
\hline 2 & (111) & $\perp$ to $(111)$ & $45^{\circ}$ from (111) & $\sqrt{3} r E$ & $86.6 \%$ \\
\hline 3 & (211) & $(1 \overline{1} \overline{1})$ & $45^{\circ}$ from $(\overline{1} 10)$ & $\sqrt[2]{\frac{2}{3} r E}$ & $81.6 \%$ \\
\hline 4 & (001) & $(110)$ or $(\overline{1} 10)$ & $45^{\circ}$ from $(001)$ & $r E$ & $50.0 \%$ \\
\hline
\end{tabular}
useful at high frequencies ( $>1 \mathrm{MHz}$ ) but it is just such a regime that is of interest for communications systems.

TABle V

Effect of orientation of electrooptic modulator bar on relative modulator efficiency 


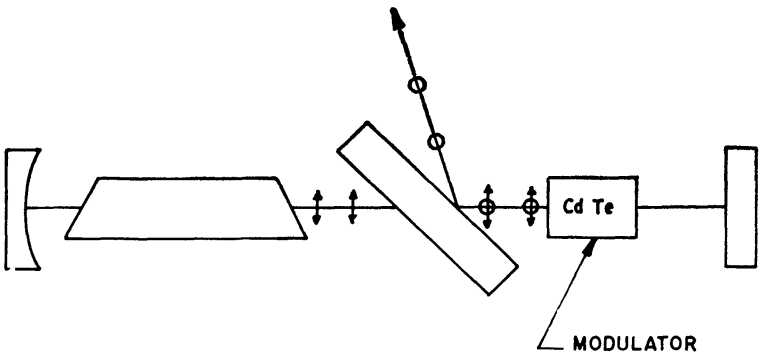

FIG. 5. - CdTe being used for internal modulation of a laser by coupling to a Brewster angle window.

Extremely short pulses (1 ns) can be generated from a $\mathrm{CO}_{2}$ laser using $\mathrm{CdTe}$ as an electrooptic gate driven by a Blumlein structure [32]. The voltage pulse is generated using a laser triggered spark gap. Power output was obtained at both the 10.4 and $9.4 \mu \mathrm{m}$ vibrational transitions. Alternatively, $\mathrm{CdTe}$ can be used to select a single pulse from a train by gating it on and then off.

In addition to being an electrooptic material, $\mathrm{CdTe}$ exhibits non-linear behavior at high power which produces harmonic generation and mixing. Patel [33] measured the non-linear coefficients for harmonic generation. The second harmonic, $P(2 \omega)$, is given by [34]

$$
P(2 \omega)=\frac{8}{\pi^{2}} \frac{\omega^{2}}{n^{3}} d^{2}\left[\frac{P(\omega)}{A}\right]^{2} l_{\mathrm{c}}^{2}
$$

where $P(\omega)$ is the input power at frequency, $\omega, n$ is the index of refraction, $d$ is the non-linear susceptibility, $A$ is the area, and $l_{\mathrm{c}}$ is the coherence length of the crystal. From the symmetry the most efficient second harmonic generation occurs for the input beam along the (110) and the electric field polarized in the (110). The coherence length was calculated to be $235 \mu \mathrm{m}$ at $10.6 \mu \mathrm{m}$ from index of refraction data [33]. McArthur and McFarlane [35] observed second harmonic generation and sum frequency mixing when using a pulsed water vapor laser in the 26 to $33 \mu \mathrm{m}$ range. The value of $d$ [36] at $28 \mu \mathrm{m}$ was about twice as large as that at $10.6 \mu \mathrm{m}$.

Using a $\mathrm{CW} \mathrm{CO} \mathrm{C}_{2}$ laser Stafsudd and Alexander [34] were able to generate the second harmonic continuously, although for an input power of $28 \mathrm{~W}$ only about $40 \mu \mathrm{W}$ output was obtained. No crystal damage was observed for power densities of $10^{5} \mathrm{~W} / \mathrm{cm}^{2}$ even though no attempt to heat sink the sample was made.

By quasi-phase matching (using a stack of CdTe plates an odd number of coherence lengths thick, each of which is rotated $180^{\circ}$ with respect to its neighbors) essentially $100 \%$ conversion to the second harmonic can be obtained [26].

Another scheme for optical modulation is to use an acoustic wave and rely on the piezo-optic constants to induce a change in the index of refraction. This technique has not been used on CdTe but the static coefficients have been measured [36]. The figure of merit for modulation, $M$, is

$$
M=\frac{n^{6} P^{2}}{\rho v^{3}}
$$

where $\rho$ is the density, $v$ is the sonic velocity, and the piezo-optic constant $\boldsymbol{P}_{11}$ is given in table IV. The value of $M$ is similar to that of GaAs but the superior transparency of CdTe would be a definite advantage for wavelengths longer than $10 \mu \mathrm{m}$.

The final modulation technique that has been used is the Franz-Keldysh effect. An applied electric field will produce a change in the absorption of interband transitions in semiconductors. CdTe at $80 \mathrm{~K}$ shows one transmission maximum, corresponding to a decrease in absorption at $1.484 \mathrm{eV}$, and a minimum corresponding to an increase at $1.62 \mathrm{eV}$ [37]. At the second, an electric field of $6 \times 10^{4} \mathrm{~V} / \mathrm{cm}$ on a $1 \mu \mathrm{m}$ thick film can produce a $35 \%$ increase in transmission. At $290 \mathrm{~K}$ the modulation magnitude is reduced by a factor of two.

3.3 LuMINESCENCE. - Another possible optical application is that of electroluminescence. Because $\mathrm{CdTe}$ has a direct bandgap (Fig. 1) it can have a strong luminescence emission. Stimulated emission has been excited by optical pumping [38], by electron beam bombardment [39] and by impact ionization [40]. It can be doped both n- and p-type so the possibility of making lasers by minority carrier injection has been attempted [41] but has not been successful to date.

3.3.1 p-n junctions. - Van Doorn and de Nobel [42] observed luminescence in p-n junctions as early as 1956 , but the emission, which peaked at $0.89 \mu \mathrm{m}(1.40 \mathrm{eV})$ at $77 \mathrm{~K}$, was rather weak. They attributed the radiation either to band-to-band transitions or to an exciton line.

Mandel and Morehead [41] were the first to produce efficient emission (external quantum efficiencies of 0.12 photons per minority carriers at $77 \mathrm{~K}$ ) from p-n junctions. The junctions were produced by the simultaneous diffusion of $\mathrm{Cd}$ and $P$ into $\mathrm{Al}$ doped $\mathrm{CdTe}$ grown from the melt. A rather long time (2 weeks) was required to diffuse the $30 \mu \mathrm{m}$ deep junction. The excess Cd diffused more rapidly than the $P$ and converts the interior of the sample into low resistivity $(0.10 \Omega . \mathrm{cm})$ n-type ; whereas, the slower $P$ produces a 1 to $10 \Omega . \mathrm{cm}$ $\mathrm{p}$-type shell. After lapping the p-layer from one side and cutting, the diodes were cleaved along the (110) planes. Electroless $\mathrm{Au}$ was used for ohmic contacts to the p-side and indium solder was used for the contact to the n-side. The $I-V$ characteristic of the diode had an $\exp (\mathrm{eV} / 2 k T)$ dependence on bias which is what is expected when recombination occurs in the space charge region.

Emission was observed at 1.41 to $1.50 \mathrm{eV}$ depending on current and temperature. The initial intensity was proportional to the current density squared, but became 
linear at high levels. The relative efficiency in the linear region was found to have the form [43]

$$
\eta=\frac{1}{1+a \exp (-\Delta E / k T)}
$$

where $E=0.1 \mathrm{eV}$ and $a=5 \times 10^{3}$. This is the relation that follows when thermal quenching of photoluminescence occurs. $\Delta E$ is a measure of the energy difference between the luminescent center and trap level and a is a measure of trap concentration [44]. Even at current densities as high as $4 \times 10^{4} \mathrm{~A} / \mathrm{cm}^{2}\left(2.5 \times 10^{23}\right.$ carriers $\left./ \mathrm{s} / \mathrm{cm}^{2}\right)$ no stimulated emission was observed [43]. The internal quantum efficiency was near unity above $2 \mathrm{~A} / \mathrm{cm}^{2}$ [45] so the absence of emission is probably due to either non planarity of the junction, self absorption, or high series resistance on the p-side.

Ishida and Tanaka [46] found that junctions formed by liquid phase epitaxy have external efficiencies near $20 \%$ at $100 \mathrm{~K}$ and $0.2 \%$ at $300 \mathrm{~K}$ (Fig. 6). A smoother

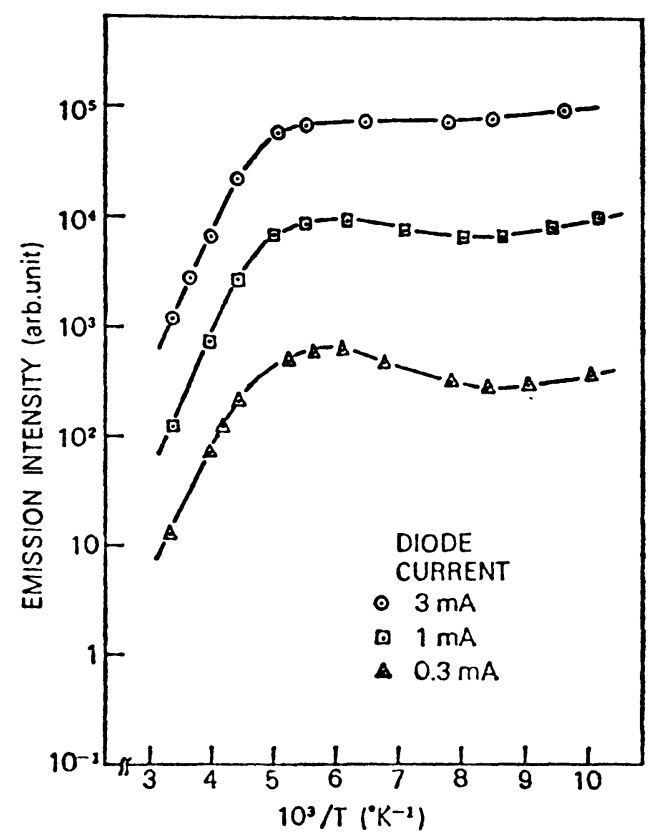

FIG. 6. - Relative electroluminescent intensity as a function of $1000 / \mathrm{T}$ for three different currents (after Ishida and Tanaka [46]).

junction and higher doping concentrations were obtained. Also the time to form a device was much shorter. A Bi solvent doped with In gave the n-type layer on the $\mathrm{p}$ substrate. Current-voltage and capacitance measurements showed a nearly abrupt junction with only a slight gradation. The depletion width was $0.3 \mu \mathrm{m}$ at zero bias.

Naumov [47] demonstrated that the recombination took place in the p-region. Because of the high resistance, a substantial voltage drop existed across the $10 \mu \mathrm{m}$ p-region, thus allowing electrons to reach the metal p-CdTe boundary and not contribute to the luminescence. In order to insure a population inversion it is probably necessary to have a lower resistivity p-region.

Investigations made by Morikawa and Yamaka [48] on diffused diodes showed similar $I-V$ characteristics. At $77 \mathrm{~K}$ they found emission peaks at $0.92,0.95$ and $0.89 \mu \mathrm{m}$ (Fig. 7). As the current density increased, the

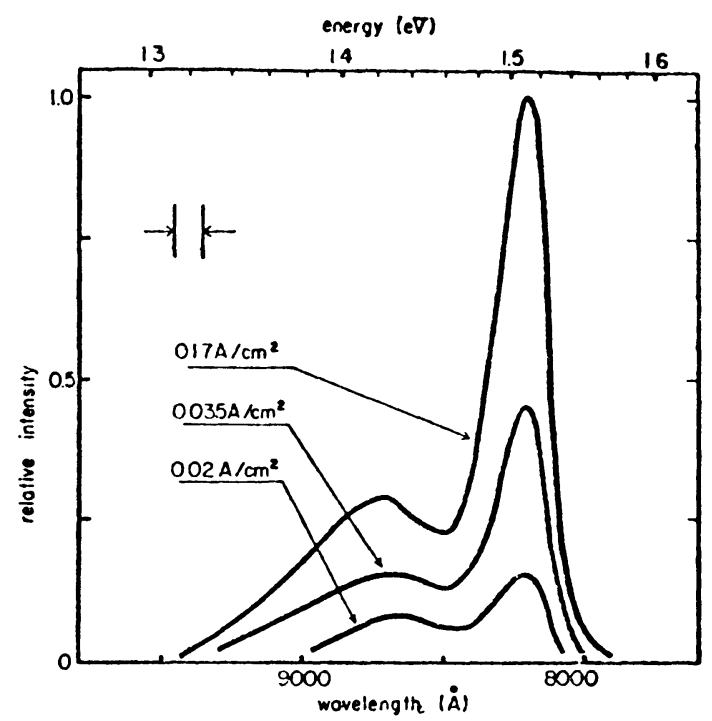

FIG. 7. - Relative electroluminescent intensity as a function of wavelength for three different currents (after Morikawa and Yamaka [48]).

short wavelength peak tends to dominate. Ishikawa and Mitsuma [49] observed just the opposite behavior, though. Chapnin [50] has also studied CdTe luminescent diodes.

The most recently reported work is apparently by Gu et al. [51, 52]. The peak at $77 \mathrm{~K}$ is caused by donoracceptor pair recombination. Their value of $\Delta E$ was only $0.05 \mathrm{eV}$ and they believe related to the depth of the $\mathrm{p}$ acceptor. The external quantum efficiencies were $0.033 \%$ at $300 \mathrm{~K}$ and $7.5 \%$ at $77 \mathrm{~K}$.

3.3.2 Electron beam pumping. - Using pulsed electron beams, extremely high pair generation rates and stimulated emission (lasing) have been obtained in CdTe [39, 53]. For example, one electron at $150 \mathrm{keV}$ will produce approximately $3.4 \times 10^{4}$ hole-electron pairs. Thus a current density in the electron beam of $2 \mathrm{~A} / \mathrm{cm}^{2}$ will generate something like $4 \times 10^{23} \mathrm{pairs} / \mathrm{cm}^{2} / \mathrm{s}$ which Vavilov [39] et al. estimate to correspond to a rate of $10^{26} / \mathrm{cm}^{3} / \mathrm{s}$. They saw bands at $1.0,1.47,1.55$ and $1.59 \mathrm{eV}$ at $10 \mathrm{~K}$. The bands at 1.0 , 1.47 and 1.55 showed thermal quenching similar to that shown in eq. (9) but the intensity of the $1.59 \mathrm{eV}$ level followed a power law, $I \sim T^{-n}$ where $n$ was 0.5 to 1.5 instead of being characterized by a thermal barrier. This level is attributed to exciton transitions which at high injection levels are equivalent to interband transitions. They were able to obtain stimulated emission even at room temperature with an electron beam current 


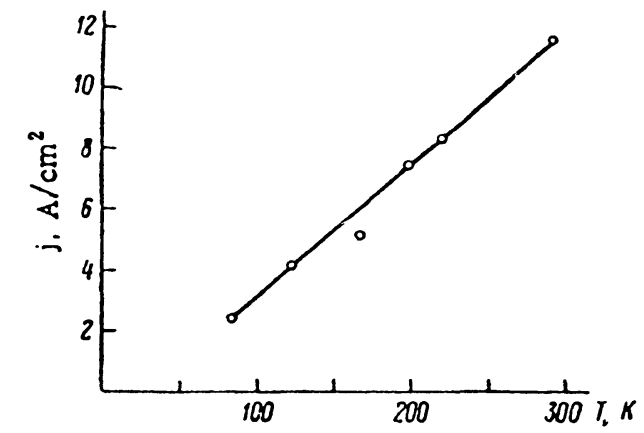

FIG. 8. - Temperature dependence of lasing threshold for $90 \mathrm{keV}$ electrons (after Vavilov et al. [53]).

density of $12 \mathrm{~A} / \mathrm{cm}^{2}$ (Fig. 8). Figure 8 shows the threshold current density as a function of temperature.

3.3.3 Optical pumping. - Using a $Q$-switched neodymium glass laser as a source of radiation, doublephoton pumping has been used to obtain laser action [38] in CdTe (Fig. 9). Line narrowing occurred for power above $1 \mathrm{MW} / \mathrm{cm}^{2}\left(6 \times 10^{24}\right.$ photons $\left./ \mathrm{cm}^{2} / \mathrm{s}\right)$.

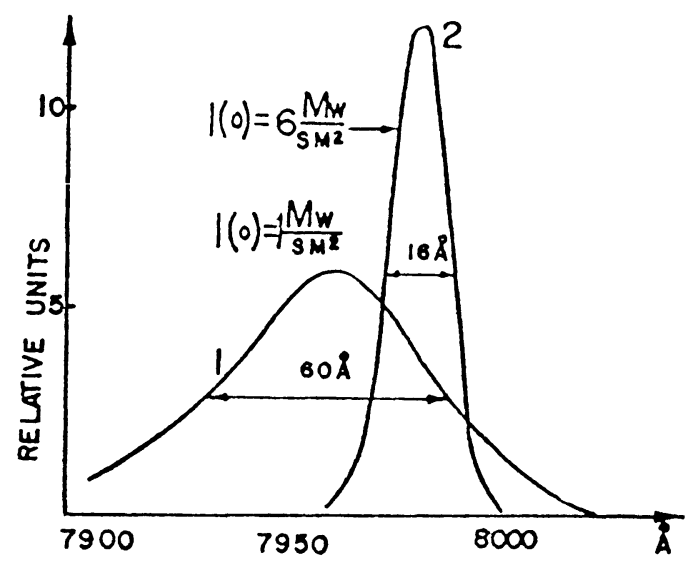

Fig. 9. - Spectral narrowing for double-photon excitation of CdTe (after Basov et al. [38]).

3.3.4 Impact ionization. - Van Atta et al. [40] have seen line narrowing occurring in n-type CdTe at room temperature. The recombination light emission was associated with breakdown at $12 \mathrm{kV} / \mathrm{cm}$ by impact ionization (Fig. 10). At room temperature the radiation peak was at approximately $0.89 \mu \mathrm{m}(1.40 \mathrm{eV})$ and was attributed to electron-hole recombination at shallow impurity centers.

3.4 Photoconductivity. - Like many of the II-VI compounds CdTe is a good photoconductor. Often the phenomenon has been exploited to look at various energy levels, i. e., materials evaluation, but only a few practical applications have been developed or suggested.

The most direct has been the fabrication of a photoconductive detector [54] designed to operate between

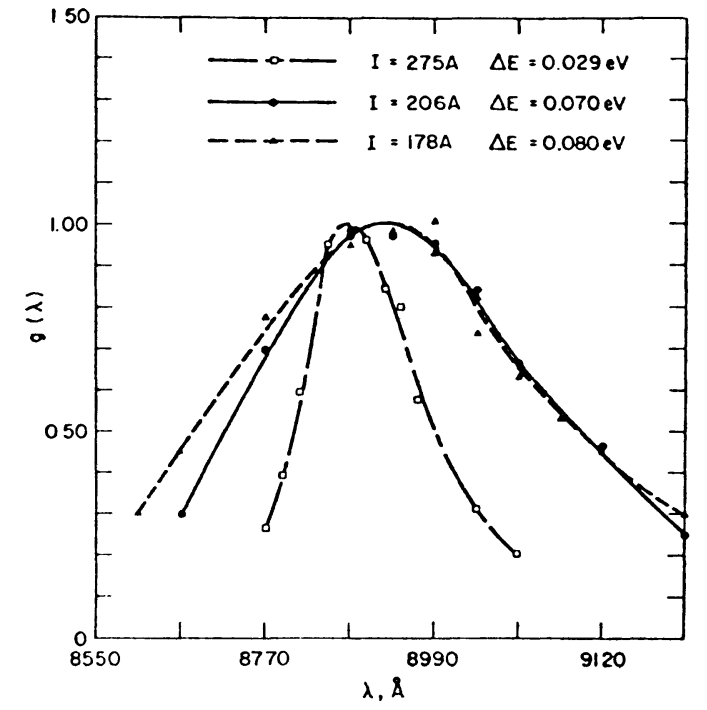

FIG. 10. - Relative optical spectra emitted from n-type CdTe at three different currents (after Van Atta et al. [40]).

room temperature and $400{ }^{\circ} \mathrm{C}$. Figure 11 shows typical response curves between 22 and $400^{\circ} \mathrm{C}$. The CdTe was initially high resistivity $\left(10^{7} \Omega . \mathrm{cm}\right)$ grown by THM, both chlorine doped and undoped. After several tem-

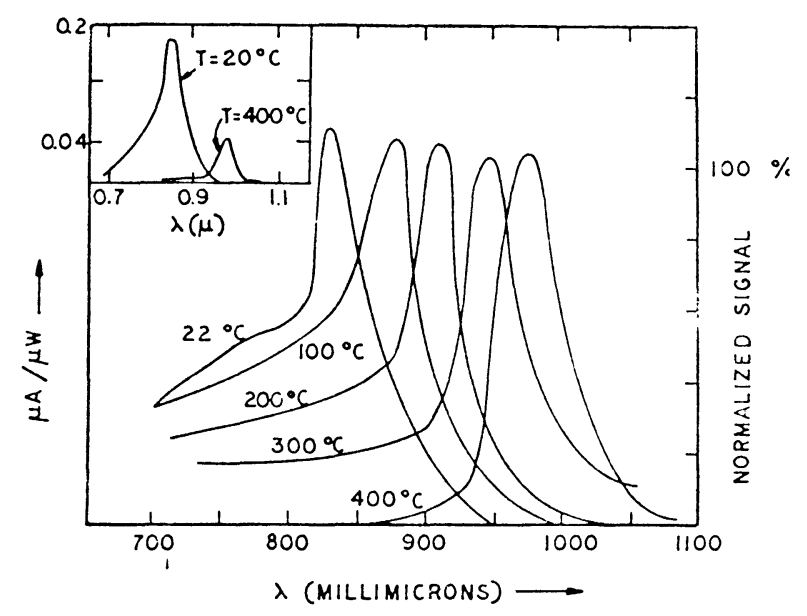

FIG. 11. - Spectral response of CdTe photoconductor for various temperatures. The insert is on an absolute scale with a fixed load of $2.2 \mathrm{k} \Omega$ (after Farrell et al. [54]).

perature cycles the resistivity had dropped to $1000 \Omega . \mathrm{cm}$ where it stabilized. Iridium proved to make a stable, ohmic contact with the device lifetime greater than $1000 \mathrm{hr}$ at $400^{\circ} \mathrm{C}$. The chlorine doped material was more photosensitive at all temperatures than the undoped CdTe. The center that sensitizes the chlorine doped photoconductor is not known.

So far no applications have been made of the persistent photoconductivity or photomemory that has been observed at low temperatures $[55,56]$.

4. Summary and conclusions. - To some extent 
the use of CdTe has not lived up to earlier expectations from the viewpoint of optical applications. The areas where it really excels are as an electrooptic modulator and optical mixer/harmonic generator in the 5 to $25 \mu \mathrm{m}$ ranges. It has some utility as a window for low power systems but for high powers at $10.6 \mu \mathrm{m}$ it is probably only second or third on the list of candidate materials.

It makes a sensitive photoconductor for use at high temperatures but it is hampered by the lack of high priority requirements.

As a p-n junction laser it probably will never make much of an impact because of the excellent performance of $\mathrm{GaAl}_{x} \mathrm{As}_{1-x}$ at similar energies. The ability to make very low resistivity p-type material with a long minority carrier lifetime and very good ohmic contacts might change this outlook.

\section{References}

[1] Randall, C. M. and Rawcliffe, R. D., Appl. Opt. 7 (1968) 213.

[2] Johnson, C. J., Sherman, G. H. and Weil, R., Appl. Opt. 8 (1969) 1667.

[3] Gentile, A. L., Kiefer, J. E., Kyle, N. R. and Winston, H. V., Mat. Res. Bull. 8 (1973) 523.

[4] Cohen, M. L. and Bergstresser, T. K., Phys. Rev. 141 (1966) 789.

[5] Kireev, P. S., Volkova, L. V., Volkov, V. V. and Platonov, Yu. V., Sov. Phys.-Semicond. 6 (1972) 109.

[6] Marple, D. T. F., Phys. Rev. 150 (1966) 728.

[7] Camassel, J., Auvergne, D., Mathieu, H., Triboulet, R. and Marfaing, Y., Solid State Commun. 13 (1973) 63.

[8] Moss, T. S., Optical Properties of Semi-Conductors (Academic Press, Inc., New York) 1956, pp. 15-33.

[9] KLIER, M., Z. Phys. 150 (1958) 49.

[10] Rupprecht, G., Phys. Rev. Lett. 12 (1964) 580.

[11] Deutsch, T. F., J. Electron. Mat. 4 (1975) 663.

[12] Sparks, M. and Sham, L. J., Solid State Commun. 11 (1972) 1451 and Phys. Rev. B 8 (1973) 3037.

[13] Brodin, M. S., Gnatenko, Yu. P., Kurik, M. V. and Matlak, V. M., Sov. Phys.-Semicond. 3 (1970) 835.

[14] Bell, R. O. and Wald, F., Proceedings of the International Symposium on CdTe (Ed. by P. Siffert and A. Cornet) Paper VI, Strasbourg (1971).

[15] Beserman, R. and Balkanski, M., J. Phys. Chem. Solids 31 (1970) 355.

[16] Vodopyanov, L. K. and Vinogradov, E. A., Crystal Lattice Defects 5 (1974) 125.

[17] Dutt, B. V., Al-Delaimi, M. and Spitzer, W. G., J. Appl. Phys. 47 (1976) 565.

[18] Slack, G. A., Ham, F. S., Chrenko, R. M., Phys. Rev. 152 (1966) 376.

[19] Vul, B. M., Ivanov, V. S., Rukavishnikov, V. A., Sal'man, V. M. and Chapnin, V. A., Sov. Phys.Semicond. 6 (1973) 1106.

[20] Baranowski, J. M., Langer, J. M. and Stefanova, S., 11th Internat. Conf. on the Phys. of Semicond. Vol. 2, Warsaw (1972) p. 1001.

[21] Vallin, J. T., Slack, G. A., Roberts, S. and Hughes, A. E., Phys. Rev. B 2 (1970) 4313.

[22] Plotnikov, A. F., Sal'man, V. M., Sokolova, A. A. and Chapnin, V. A., Tellurid Kadmiya (Ed. by B. M. Vul) (1968) from Chem. Abstracts.

[23] Strauss, A. J. and Iseler, G. W., Solid State Research, Lincoln Laboratory, MIT, Lexington, MA, Second Quarter (1972) pp. 23-26.

[24] KortKe, M., Rev. Sci. Instrum. 42 (1971) 1235.

[25] LADD, L. S., Infrared Phys. 6 (1966) 145.

[26] JoHnson, C. J., II-VI Incorporated, private communication.

[27] Bates, H. E., Mobil Tyco Solar Energy Corporation, private communication.
[28] Kiefer, J. E. and Yariv, A., Appl. Phys. Lett. 15 (1969) 26

[29] Johnson, C. J., Proc. IEEE 56 (1968) 1719.

[30] Spears, D. L., Strauss, A. J. and Ryan, J. L., Solid State Research, Lincoln Laboratory, MIT, Lexington, MA, First Quarter (1976), pp. 3-5.

[31] Kiefer, J. E., Nussmeier, T. A. and Goodwin, F., IEEE, J. Quantum Electron. QE-8 (1972) 173.

[32] Figueira, J. F. and SutPhin, H. D., Appl. Phys. Lett. 25 (1974) 661.

[33] Patel, C. K. N., Phys. Rev. Lett. 16 (1966) 613.

[34] Stafsudd, O. M. Jr. and AleXander, D. H., Appl. Opt. 10 (1971) 2566.

[35] McArthur, D. A. and McFarlane, R. A., Appl. Phys. Lett. 16 (1970) 452.

[36] WeIL, R. B. and Sun, M. J., Proceedings of the International Symposium on CdTe (Ed. by P. Siffert and A. Cornet) Paper XIX, Strasbourg (1971).

[37] Babonas, G. A., Krivayte, E. Z. and Shileyka, A. Yu., Sov. J. Opt. Tech. 9 (1970) 401.

[38] Basov, N. G. et al., J. Phys. Soc. Japan 21 (1966) 277.

[39] Vavilov, V. S. and Nolle, E'. L., Sov. Phys.-Solid State 8 (1966) 421.

[40] Van Atta, L. B., Picus, G. S. and Yariv, A., Appl. Phys. Lett. 12 (1968) 84.

[41] Mandel, G. and Morehead, F. F., Appl. Phys. Lett. 4 (1964) 142.

[42] VAN Doorn, C. Z. and DE Nobel, D., Physica XX (1956) 338.

[43] Morehead, F. F., J. Appl. Phys. 37 (1966) 3487.

[44] Sze, S. M., Physics of Semiconductor Devices (WileyInterscience, New York) 1969, pp. 629-632.

[45] Golubev, G. P., Sov. Phys.-Solid State 12 (1971) 2486.

[46] Ishida, H. and Tanaka, K., Proceed. 3rd Conf. on Solid State Devices, Tokyo (1971) p. 117.

[47] Naumov, G. P., Sov. Phys. Solid State 9 (1967) 46.

[48] Morikawa, K. and Yamaka, E., Japan. J. Appl. Phys. 7 (1968) 243.

[49] Ishikawa, R. and Mitsuma, T., Japan. J. Appl. Phys. 5 (1966) 1171.

[50] Chapnin, V. A., Sov. Phys.-Semicond. 2 (1968) 212.

[51] Gu, J., Kitahara, T., Fujita, S. and SaKaguchi, T., Japan. J. Appl. Phys. 14 (1975) 499.

[52] Gu, J., Kitahara, T. and Sakaguchi, T., Japan. J. Appl. Phys. 12 (1973) 1460.

[53] Vavilov, V. S., Nolle, E'. L., Golubev, G. P., Mashtakov and Tsarapaeva, E. I., Sov. Phys.-Solid State 9 (1967) 657.

[54] Farrell, R., Entine, G., Wilson, F. and Wald, F. V., J. Electron. Mat. 3 (1974) 155.

[55] Karpenko, V. P., Kasherininov, P. G. and Matveev, $O$. A., Sov. Phys.-Semicond. 4 (1970) 794.

[56] Strauss, A. J., Proceedings of the International Symposium on CdTe (Ed. by P. Siffert and A. Cornet) Paper I, Strasbourg (1971). 